\title{
Acute and selective regulation of glyceroneogenesis and cytosolic phosphoenolpyruvate carboxykinase in adipose tissue by thiazolidinediones in type 2 diabetes
}

\author{
T. Cadoudal • J. M. Blouin • M. Collinet • F. Fouque • \\ G. D. Tan • E. Loizon • E. G. Beale • K. N. Frayn • \\ F. Karpe $\cdot$ H. Vidal • C. Benelli $\cdot$ C. Forest
}

Received: 13 September 2006 / Accepted: 10 November 2006 / Published online: 23 January 2007

(C) Springer-Verlag 2007

\begin{abstract}
Aims/hypothesis Regulation of glyceroneogenesis and its key enzyme cytosolic phosphoenolpyruvate carboxykinase (PEPCK-C) plays a major role in the control of fatty acid release from adipose tissue. Here we investigate the effect of rosiglitazone on the expression of genes involved in fatty acid metabolism and the resulting metabolic consequences. Materials and methods Rosiglitazone was administered to Zucker $f a l f a$ rats for 4 days and to 24 diabetic patients for 12 weeks, then mRNA expression for the genes encoding PEPCK-C, mitochondrial PEPCK, adipocyte lipid-binding protein, glycerol kinase, lipoprotein lipase and glycerol-3-
\end{abstract}

Electronic supplementary material Supplementary material is
available in the online version of this article at http://dx.doi.org/
$10.1007 / \mathrm{s} 00125-006-0560-5$ and is accessible to authorised users.

T. Cadoudal · J. M. Blouin · M. Collinet $\cdot$ F. Fouque $\cdot$ C. Benelli $\cdot$

C. Forest $(\bowtie)$

INSERM UMR-S 530/747; Université Paris Descartes,

Centre Universitaire des Saints-Pères,

45 rue des Saints-Pères,

F-75006 Paris, France

e-mail: claude.forest@univ-paris5.fr

G. D. Tan $\cdot$ K. N. Frayn $\cdot$ F. Karpe

Oxford Centre for Diabetes Endocrinology and Metabolism,

Churchill Hospital, University of Oxford,

Oxford, UK

E. Loizon $\cdot$ H. Vidal

INSERM, U449; INRA 1235; Université Claude Bernard,

Faculté de Médecine R. Laennec,

Lyon, France

E. G. Beale

Department of Cell Biology and Biochemistry,

Texas Tech University Health Sciences Center,

Lubbock, TX, USA phosphate dehydrogenase was examined in s.c. adipose tissue by real-time RT-PCR. Glyceroneogenesis was determined using $\left[1-{ }^{14} \mathrm{C}\right]$ pyruvate incorporation into lipids. Cultured adipose tissue explants from overweight women undergoing plastic surgery were incubated with rosiglitazone for various times before mRNA determination and analysis of PEPCK-C protein, activity and glyceroneogenesis.

Results Rosiglitazone administration to rats induced the expression of the gene encoding PEPCK-C mRNA ( $P C K 1)$ and PEPCK-C activity in adipose tissue with a resulting 2.5-fold increase in glyceroneogenesis. This was accompanied by an improvement in dyslipidaemia as demonstrated by the decrease in plasma NEFAs and triacylglycerol. In rosiglitazone-treated diabetic patients, $P C K 1$ mRNA was raised 2.5 -fold in s.c. adipose tissue. Rosiglitazone treatment of adipose tissue explants from overweight women caused a selective augmentation in PCK1 mRNA which reached a maximum of 9-fold at $14 \mathrm{~h}$, while mRNA for other genes remained unaffected. Experiments with inhibitors showed a direct and transcription-only effect, which was followed by an increase in PEPCK-C protein, enzyme activity and glyceroneogenesis.

Conclusions/interpretation These results favour adipocyte glyceroneogenesis as the initial thiazolidinedione-responsive pathway leading to improvement in dyslipidaemia.

Keywords Adipose tissue - Fatty acids . Glyceroneogenesis · Phosphoenolpyruvate carboxykinase . Re-esterification - Type 2 diabetes

Abbreviations
$\begin{array}{ll}\text { AP2 } & \text { adipocyte lipid-binding protein } \\ \text { DRB } & 5,6 \text {-dichloro-1 } \beta \text {-D-ribofuranosyl } \\ & \text { benzimidazole }\end{array}$




\begin{tabular}{|c|c|}
\hline FABP4 & gene encoding AP2 \\
\hline GAPDH & $\begin{array}{l}\text { glyceraldehyde-3-phosphate } \\
\text { dehydrogenase }\end{array}$ \\
\hline G3P & glycerol 3-phosphate \\
\hline PPDH & glycerol-3-phosphate dehydrogena \\
\hline YK & glycerol kinase \\
\hline $\mathrm{L}$ & lipoprotein lipase \\
\hline$C K 1$ & gene encoding PEPCK-C \\
\hline PCK2 & gene encoding PEPCK-M \\
\hline EPCK & phosphoenolpyruvate carboxykinase \\
\hline EPCK-C & cytosolic PEPCK \\
\hline EPCK-M & mitochondrial PEPCK \\
\hline PAR $\gamma$ & $\begin{array}{l}\text { peroxisome proliferator-activated } \\
\text { receptor gamma }\end{array}$ \\
\hline & retinoid X receptor \\
\hline
\end{tabular}

\section{Introduction}

Thiazolidinediones are oral antidiabetic drugs which increase insulin sensitivity, thereby reducing hyperglycaemia in type 2 diabetes. Although much is known about the molecular mechanisms of thiazolidinedione action, questions remain about their physiological targets. Thiazolidinediones bind to and activate the gamma isoform of peroxisome proliferator-activated receptor (PPAR $\gamma)$, which regulates the expression of a variety of genes involved in metabolism in multiple insulin-sensitive tissues [1, 2]. Several lines of evidence have led to the idea that the thiazolidinedione-mediated increase in insulin sensitivity is secondary to the direct effect of this drug on adipose tissue. When administered in vivo to animal models of obesity and diabetes, thiazolidinediones augment fat mass due to an increase in fatty acid storage and a stimulated adipogenesis, as observed by metabolic studies [3, 4]. A concomitant decrease in circulating NEFAs usually occurs [2]. The thiazolidinedione lowering of plasma NEFAs and triacylglycerol has therefore been considered as the major factor responsible for the insulin-sensitising effect of these drugs in rodents $[2,5]$. The situation looks more complex in humans in which either a decrease [6,7], a trend towards a decrease [8] or no effect [9] on plasma NEFAs has been reported depending on the type and concentration of drugs, the duration of treatment and the nutritional background, i.e. fasting or postprandial.

Plasma NEFA levels represent a balance between their release from triacylglycerol stores in adipose tissue and their clearance into tissues that need energy. Since thiazolidinediones seem to have little or no effect on basal rates of lipolysis in rodents and humans [7], the decrease in plasma NEFA is probably due to increased fatty acid clearance, via oxidation and/or esterification. Recent data clearly demonstrated that 2 months of treatment with thiazolidinedione of patients with type 2 diabetes mellitus induced a coordinated upregulation of genes involved in fatty acid uptake, $\beta$-oxidation, electron transport and oxidative phosphorylation in adipose tissue [10]. However, it is worth noting that $30 \%$ or more of the lipolytic NEFAs are immediately re-esterified into newly synthesised triacylglycerol in adipose tissue in rats and humans [11, 12]. This apparent 'futile cycle' of simultaneous lipolysis and re-esterification creates an important mechanism for energy homeostasis [13]. Glycerol-3-phosphate (G3P) is required as a substrate for fatty acid re-esterification into triacylglycerol [14]. Under lipolytic conditions during fasting or stress, G3P cannot arise from glucose transport and metabolism. Glycerol phosphorylation could be involved in G3P production, although glycerol kinase (GYK) activity is very weak in adipose tissue under physiological conditions [15]. Glyceroneogenesis, the pathway described by Hanson, Reshef and their colleagues more than 35 years ago, actually allows G3P synthesis from pyruvate, lactate or certain amino acids [16]. Lactate is the most probable physiological substrate for G3P synthesis because of the large amount of this metabolite in plasma during fasting [17]. This pathway occurs also in liver, in addition to gluconeogenesis [18]. Recent data identified glyceroneogenesis as a thiazolidinedione target in cultured rat adipocytes and adipose tissue, which was the result of induction of its key enzyme, the cytosolic isoform of phosphoenolpyruvate carboxykinase (PEPCK-C) [19]. In cultured explants from human s.c. adipose tissue, the prototype thiazolidinedione rosiglitazone increased the expression of the gene endoing PEPCK-C (PCK1) and glyceroneogenesis [20, 21]. It was also shown that pioglitazone-treated type 2 diabetes patients presented an increase in adipose tissue PCK1 mRNA [22]. However, the respective involvement of various adipocyte proteins involved in lipid metabolism in response to thiazolidinedione in diabetic and non-diabetic humans and rodents remained unclear.

Collectively, the available data led us to postulate that induction of PEPCK-C/glyceroneogenesis is the key mechanism by which thiazolidinediones suppress fatty acid release. This hypothesis needed to be tested in a single coordinated study that addressed each of the known pathways affecting fatty acid release. Thus the aim of this work was: (1) to quantify the effect of thiazolidinediones on the expression of genes related to fatty acid metabolism in a rodent model of obesity with insulin resistance and dyslipidaemia (the Zucker rat) and in s.c. adipose tissue from normal subjects and from type 2 diabetes humans; and (2) to analyse the metabolic consequences of the observed changes. The results of this study support the hypothesis. 


\section{Materials, subjects and methods}

Materials DMEM was from Invitrogen (Cercy-Pontoise, France). Rosiglitazone (BRL 49653) was a gift from GlaxoSmithKline (Brentford, Middlesex, UK) and commercially available from Alexis Biochemicals (Coger; Paris, France). All other products were purchased from Sigma (L'Isle d'Abeau Chesnes, France).

Animals and treatments Male Zucker fatty rats and their lean littermates were purchased from Charles River laboratories (L'Arbresle, France). Rats were kept on a 12-h light-dark cycle at constant room temperature. Conventional laboratory diet and tap water were provided freely until $4 \mathrm{~h}$ before the animals were killed, when food was withdrawn. At the time of experiment, eight 8-weekold rats were used per treatment group. Rats were given a dose of $5 \mathrm{mg} \mathrm{kg}^{-1}$ day $^{-1}$ rosiglitazone (maleate) or vehicle $(0.5 \%$ methylcellulose $)$ via oral gavage in the morning. After 4 days of treatment, animals were fasted for $4 \mathrm{~h}$, then killed. Plasma was obtained via the jugular vein and aliquots were stored at $-20^{\circ} \mathrm{C}$ for further glucose (AccuCheck; Roche, Meylan, France), insulin (Ultrasensitive Rat Insulin ELISA; EuroBio, Courtaboeuf, France), triacylglycerol (Vitros Chemistry System; Ortho-Clinicals Diagnostics, Raritan, NJ, USA), NEFA (Free Fatty Acids Half Micro Test; Roche) and glycerol (Glycerol UV-Method; R-Biopharm, Saint-Didier au Mont d'Or, France) determinations. Samples of s.c., periepididymal and retroperitoneal adipose tissues were dissected and frozen at $-80^{\circ} \mathrm{C}$ for further analyses. For s.c. samples, a region of the flank was arbitrarily defined, allowing an easy weight comparison from rat to rat. The protocol for the animal studies was conducted according to the French Guidelines for the Care and Use of Experimental Animals.

Diabetic patients Twenty-four patients with type 2 diabetes, treated with diet alone, participated in the study. Metabolic parameters of the patients have been previously published [8] and are included, with permission, in the Electronic Supplementary Material (ESM) Table 1.

Human adipose tissue explants Explants of s.c. adipose tissue were obtained from eight women undergoing elective surgery. They were aged $45.7 \pm 4.4$ years (mean \pm SEM) and had a BMI of $30.3 \pm 1.4 \mathrm{~kg} / \mathrm{m}^{2}$. None of the subjects suffered from known metabolic or malignant diseases, nor were they taking medications known to alter adipocyte metabolism. The study was performed according the Declaration of Helsinki. All the patients gave informed written consent.

Adipose tissue specimens from the s.c. region were obtained within $15 \mathrm{~min}$ after the onset of surgery. About $5 \mathrm{~g}$ of tissue were cut in about $20 \mathrm{mg}$ fragments and cultured in DMEM containing $12.5 \mathrm{mmol} / 1$ glucose, $200 \mathrm{IU} / \mathrm{ml}$ penicillin, $50 \mathrm{mg} / 1$ streptomycin and $10 \% \mathrm{FCS}$ at $37^{\circ} \mathrm{C}$ in $10 \% \mathrm{CO}_{2}$. After a 1 -h preincubation, rosiglitazone was added or not for different times. Explants were frozen before further studies.

RNA analysis Total RNA was extracted from rat adipose tissues by the method of Chomczynski and Sacchi [23] and from human adipose tissue explants using the Rneasy total RNA kit from Qiagen (Courtaboeuf, France).

Total RNA $(1.25 \mu \mathrm{g})$ was reverse transcribed using a High Capacity cDNA Archive kit from Applied Biosystems (Courtaboeuf, France). cDNAs were amplified in an ABI prism 7900 HT (Applied Biosystems) using SYBR green, and were analysed with the SDS 2.1 real-time detection system software. Ribosomal 18S RNA (Rnrl) and glyceraldehyde-3-phosphate dehydrogenase $(G A P D H)$ mRNA were used to normalise cDNA. Quantification of mRNA was carried out by comparison of the number of cycles required to reach reference and target threshold values $(\delta-\delta \mathrm{Ct}$ method). Sequences of the sense and antisense oligonucleotides corresponding to the different tested genes are given in Table 1 .

Enzyme assays Freshly obtained adipose tissues were homogenised in ice-cold $10 \mathrm{mmol} / 1$ Tris- $\mathrm{HCl}$ buffer, pH 7.4, containing $250 \mathrm{mmol} / 1$ sucrose, $1 \mathrm{mmol} / \mathrm{l}$ EDTA and $1 \mathrm{mmol} / \mathrm{l}$ dithiothreitol. After centrifugation of the homogenate at $800 \times g$ for $10 \mathrm{~min}$, the supernatant was decanted and centrifuged at $10,000 \times g$ for $15 \mathrm{~min}$ to pellet the mitochondrial fraction. This fraction was washed and resuspended in the presence of $0.5 \%$ Triton X-100. The cytosolic fraction was obtained by centrifugation at $24,000 \times g$ for $45 \mathrm{~min}$. The relative enrichment in mitochondrial vs cytosolic fraction was monitored using the mitochondrial-specific marker, citrate synthase. Citrate synthase activity in the cytosolic fraction was one-tenth of that obtained in the mitochondrial fraction $(2,146 \pm 215 \mathrm{nmol}$ $\left.\min ^{-1} \mathrm{mg}^{-1} ; n=11\right)$. PEPCK activity was assayed in the cytosolic fraction according to the method of Chang and Lane [24]. Citrate synthase activity was measured by spectrophotometry in the presence of 5,5'-dithiobis-(2nitro-benzoate) as previously described [25].

Metabolic studies Adipose tissue (about $200 \mathrm{mg}$ ) was cut into pieces of about $20 \mathrm{mg}$ and incubated in 6-well plates in a humidified atmosphere of $10 \% \mathrm{CO}_{2}$ at $37^{\circ} \mathrm{C}$ in $1.5 \mathrm{ml}$ of glucose-free DMEM containing 3\% (w/v) fatty acid-free BSA and $5 \mathrm{mmol} / 1$ pyruvate. $\left[1-{ }^{14} \mathrm{C}\right]$ pyruvate $\left(2 \times 10^{4} \mathrm{~Bq} / \mathrm{ml}\right)$ was used at an isotopic dilution of $1 / 250$. After $2 \mathrm{~h}$, fragments were rinsed and frozen in liquid nitrogen before lipid 
Table 1 Primer sequences of RNA tested in real-time RT-PCR

\begin{tabular}{|c|c|c|c|}
\hline RNA & Accession number & Forward primer & Reverse primer \\
\hline \multicolumn{4}{|l|}{ Rat } \\
\hline Fabp4 & AF 144756 & 5'-AACACCGAGATTTCCTT-3' & 5'-ACACATTCCACCACCAG-3' \\
\hline Gyk & NM 024381 & 5'-GGAGACCAGCCCTGTTAAGCT-3' & 5'-GTCCACTGCTCCCACCAATG-3' \\
\hline Lpl & NM 12598 & 5'-AGGACCCCTGAAGACAC-3' & 5'-GGCACCCAACTCTCATA-3' \\
\hline Pck1 & NM 198780 & 5'-TGTTGGCTGGCTCTCACTG-3' & 5'-ACTTTTGGGGATGGGCAC-3' \\
\hline Pck2 & XM 1055522 & 5'-AGGCTGGAAAGTGGAGTGTG-3' & 5'-GTGGAAGAGGCTGGTCAATG-3' \\
\hline Rnr1 & X01117 & 5'-TCCCCCAACTTCTTAGAGG-3' & 5'-CTTATGACCCGCACTTACTG-3' \\
\hline \multicolumn{4}{|l|}{ Human } \\
\hline FABP4 & NM 001442 & 5'-GCATGGCCAAACCTAACATGA-3' & 5'-CCTGGCCCAGTATGAAGGAAA-3' \\
\hline GAPDH & NM 002046 & 5'-TCCCCCAACTTCTTAGAGG-3' & 5'-CTTATGACCCGCACTTACTG-3' \\
\hline GPD1 & NM 005276 & 5'-GAGGTGGCTGATGAGAAG-3' & 5'-CTGTGATACGGAAGTTTGG-3' \\
\hline GYK & NM 203391 & 5'-TGGTGGCTGCATCAATAAAA-3' & 5'-TTTTTCAATGAGTGCTGAATGG-3' \\
\hline LPL & NM 000237 & 5'-AGGACCCCTGAAGACAC-3' & 5'-GGCACCCAACTCTCATA-3' \\
\hline PDK4 & NM 002612 & 5'-TGCCAATTTCTCGTCTGTATG-3' & 5'-AAAAACAGATGGAAAACTGAGG-3' \\
\hline PCK1 & NM 002591 & 5'-GCTCTGAGGAGGAGAATGG-3' & 5'-TGCTCTTGGGTGACGATAAC-3' \\
\hline PCK2 & NM 004563 & 5'-CTGAGGCTGAGAATACTGC-3' & 5'-CCGCTGAGAAGGAGTTAC-3' \\
\hline
\end{tabular}

The abbreviations of the genes, their accession number and $5^{\prime}$ to $3^{\prime}$ nucleotide sequences of the forward and reverse primers are presented

extraction, according the simplified method of Bligh and Dyer [26]. The subsequent $\left[1-{ }^{14} \mathrm{C}\right]$ pyruvate incorporation was estimated by counting the radioactivity associated with the fragments.

Protein analysis Protein concentrations were determined using the Bradford method with BSA as standard [27].

Image quantification and data analysis Quantitative results were obtained by densitometry in an image analysis system. The non-parametric Mann-Whitney $U$ test for pairwise comparisons was applied due to the small number of experiments. Analyses were performed using the StatView 4.01 Non-FPU (Abacus Concepts, 1992-1993; Berkeley, CA, USA) statistical package. A value of $p<0.05$ was considered statistically significant.

\section{Results}

Effect of rosiglitazone administration to fa/fa rats on gene expression in adipose tissues The obese ( $f a / f a)$ Zucker rat is frequently used as a model of the insulin-resistant or prediabetic state. These rats exhibit impaired glucose tolerance, hyperphagia, hyperinsulinaemia and hyperlipidaemia associated with an increase in body and adipose tissue weight (Table 2). Although not overly hyperglycaemic, the $f a l f a$ rat exhibits an abnormal glucose profile after feeding when compared with its lean counterpart, which is associated with a small but consistent and significantly elevated glycated haemoglobin level.

In this model, we explored the expression of two genes involved in G3P synthesis, Pck1 and Gyk, in s.c., periepididymal and retroperitoneal adipose tissues and compared their expression with that of other adipocyte genes, such as Fabp 4 coding for the adipocyte lipid-binding protein (AP2) and $\mathrm{Lpl}$ coding for lipoprotein lipase (LPL). As previously observed [28], $\mathrm{Lpl}$ and $\mathrm{Fabp} 4$ mRNAs were induced about 3.5- and 7.0-fold, respectively, in s.c. adipose tissue from Zucker fatty rats, when compared with their lean counterparts (Fig. 1a). Pck1 expression was also induced about 3.5-fold while that of Gyk showed a $60 \%$ decrease and that of Pck2 coding for mitochondrial PEPCK (PEPCK-M) was not modified. In the other two adipose tissue depots, no change was observed in the expression of these different genes (Fig. 1b,c).

Table 2 Effect of rosiglitazone treatment on metabolic parameters

\begin{tabular}{lccc}
\hline & $\mathrm{Fa} / ?$ & $\mathrm{fa} / \mathrm{fa}$ & $\begin{array}{l}\mathrm{fa} / \mathrm{fa}+ \\
\text { rosiglitazone }\end{array}$ \\
\hline Body weight $(\mathrm{g})$ & $276.7 \pm 6.5$ & $320.1 \pm 7.1^{*}$ & $321.3 \pm 5.1$ \\
Adipose tissue weight $(\mathrm{g})$ & & \\
Subcutaneous & $3.7 \pm 0.44$ & $20.2 \pm 2.01^{*}$ & $20.6 \pm 2.02$ \\
Periepididymal & $1.3 \pm 0.09$ & $3.51 \pm 0.15^{*}$ & $3.91 \pm 0.16$ \\
Retroperitoneal & $1.33 \pm 0.13$ & $3.23 \pm 0.2^{*}$ & $3.77 \pm 0.24$ \\
Glucose $(\mathrm{mmol} / \mathrm{l})$ & $8.89 \pm 1.73$ & $6.89 \pm 0.71$ & $9.13 \pm 1.30$ \\
Insulin $(\mathrm{pmol} / \mathrm{l})$ & $2.54 \pm 0.49$ & $11.62 \pm 2.05^{*}$ & $3.98 \pm 0.61^{* * *}$ \\
NEFAs $(\mu \mathrm{mol} / \mathrm{l})$ & $211 \pm 3$ & $192 \pm 29$ & $119 \pm 35^{* *}$ \\
Triacylglycerol & $560 \pm 80$ & $1350 \pm 161^{*}$ & $880 \pm 91^{* *}$ \\
$(\mu \mathrm{mol} / \mathrm{l})$ & & & \\
\hline
\end{tabular}

Eight-week-old male lean $(F a /$ ? $)$ and fatty $(f a / f a)$ Zucker rats were fed a diet with or without rosiglitazone $\left(5 \mathrm{mg} \mathrm{kg}^{-1}\right.$ day $\left.^{-1}\right)$ for 4 days. Blood samples and adipose tissues were collected for analyses. Data are means $\pm \operatorname{SEM}$ ( $n=8$ for each group)

${ }^{*} p<0.001$ vs $F a /$ ? rats

$* * p<0.05$ vs $f a / f a$ rats

$* * * p<0.001$ vs falfa rats 

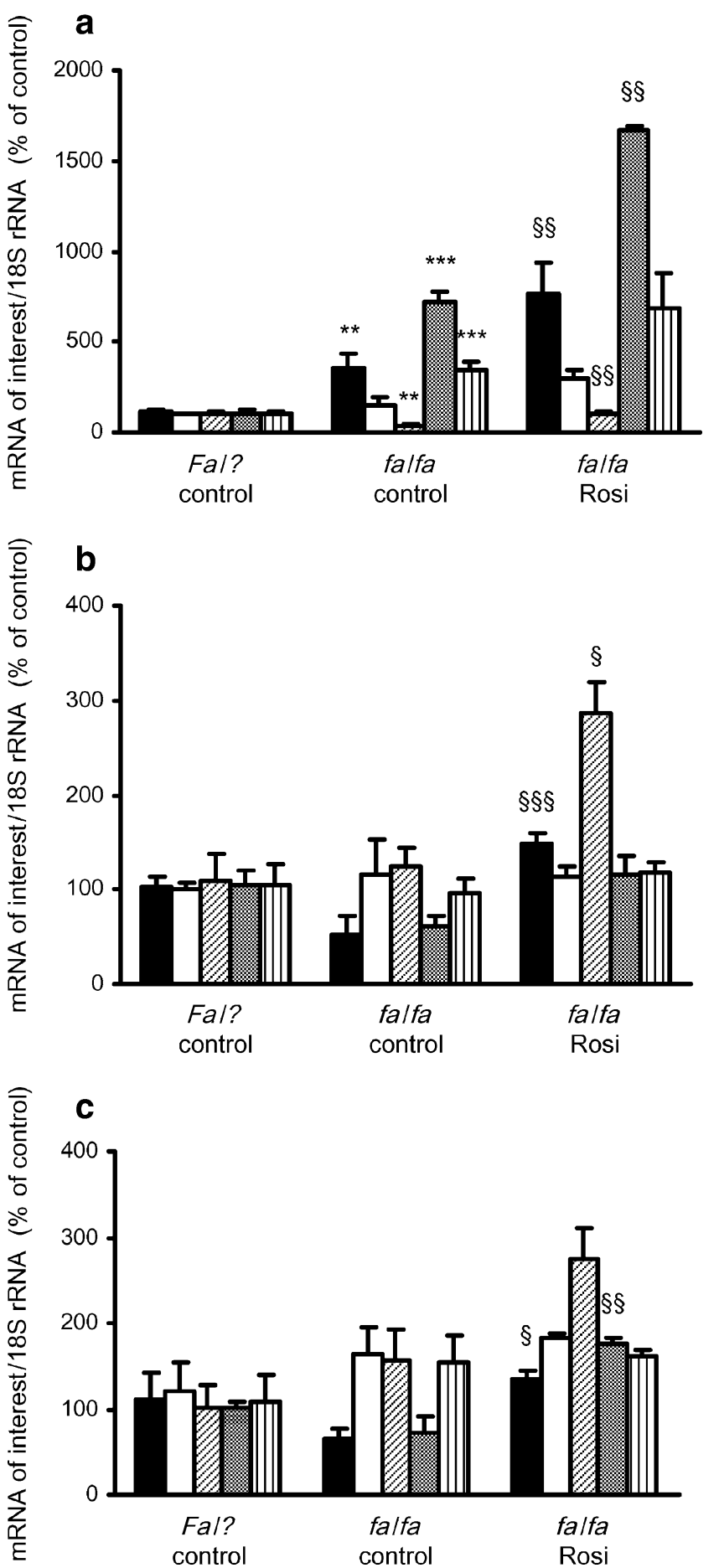

Fig. 1 Effect of rosiglitazone (Rosi) treatment on gene expression in adipose tissues. Subcutaneous (a), periepididymal (b) and retroperitoneal (c) adipose tissues were collected from rats treated with or without rosiglitazone $\left(5 \mathrm{mg} \mathrm{kg}^{-1} \mathrm{day}^{-1}\right)$ for 4 days. Pck1 (black bars), Pck2 (white bars), Gyk (hatched bars), Fabp4 (grey bars) and Lpl (vertical hatched bars) mRNA concentrations were analysed by realtime RT-PCR. Data were normalised to Rnr1 rRNA (18S) and expressed as a percent of the value obtained with lean rats. Data points in triplicate are means \pm SEM from four rats in each group. $* * p<0.01$ vs $F a /$ ? rats; $* * * p<0.001$ vs $F a /$ ? rats; $\S p<0.05$ vs $f a / f a$ rats; $\S \S p<0.01$ vs $f a l f a$ rats; $\S \S \S p<0.001$ vs falfa rats
Treating fatty Zucker male rats with rosiglitazone for 4 days significantly lowered the elevated serum lipid levels (Table 2). As expected, serum NEFA levels decreased from $192 \pm 29$ to $119 \pm 35 \mu \mathrm{mol} / 1$ after treatment $(p<0.05)$ and serum triacylglycerols decreased from $1,350 \pm 161$ to $880 \pm$ $91 \mu \mathrm{mol} / 1(p<0.05)$. Rosiglitazone did not have any impact on weight gain in these 4-day-treated rats. In s.c. adipose tissue from fatty Zucker rats, rosiglitazone treatment resulted in a coordinated increase of about twofold in Pck1, Gyk and Fabp4 mRNAs and a trend towards an increase for $L p l$ (Fig. 1a). For periepididymal and retroperitoneal adipose tissue, expression of only Pck1 and Gyk either increased or showed a trend towards an increase (Fig. 1b,c). Altogether these results show that Pckl is clearly the most constantly responsive to rosiglitazone whatever the adipose tissue localisation. In contrast, expression of the liver Pckl remained non-significantly altered by rosiglitazone treatment when compared with basal values obtained with untreated obese rats $(147 \pm 14$ vs $107 \pm 21 \%$ of the lean rat level).

We wondered whether the rosiglitazone-induced increases in Pck1 and Gyk mRNAs were linked to variations in NEFA and glycerol release from incubated s.c. adipose tissue. As shown in Fig. 2a, glycerol release remained unchanged while NEFA output was drastically reduced by twofold, showing that glyceroneogenesis was stimulated, whereas glycerol phosphorylation was not. We thus decided to focus on glyceroneogenesis and monitored incorporation of radiolabelled pyruvate into triacylglycerols. $\left[1-{ }^{14} \mathrm{C}\right]$ pyruvate was chosen because, in contrast to $\mathrm{C}_{2}$ or $\mathrm{C}_{3}$-labelled molecules, the $\mathrm{C}_{1}$ carbon of pyruvate is conserved in G3P synthesis and is thus a specific marker of glyceroneogenesis [29]. Rosiglitazone indeed induced pyruvate incorporation into triacylglycerol from $42.4 \pm 6.4$ to $104.4 \pm 9.7 \mathrm{nmol} \mathrm{h}^{-1} \mathrm{~g}^{-1}$ tissue (Fig. 2b). Results very similar to those shown with s.c. adipose tissue were obtained with periepididymal and retroperitoneal adipose tissue (not shown). To determine whether the observed reduction in NEFA output was related to variations in PEPCK-C activity, we monitored its activity in the various localisations of adipose tissue and in response to rosiglitazone treatment. PEPCK-C activities were similar in the s.c., periepididymal and retroperitoneal adipose tissue and were increased 1.5- to 2-fold by rosiglitazone in Zucker fatty rats (Fig. 2c).

Effect of rosiglitazone on PCK1 expression in type 2 diabetes patients In order to explore whether PCK1 responded to rosiglitazone in insulin-resistant humans as in rodents, we used the previously described cohort of type 2 diabetes patients in whom metabolic studies were conducted [8]. In this double-blind, placebo-controlled crossover study the effect of rosiglitazone was evaluated. 

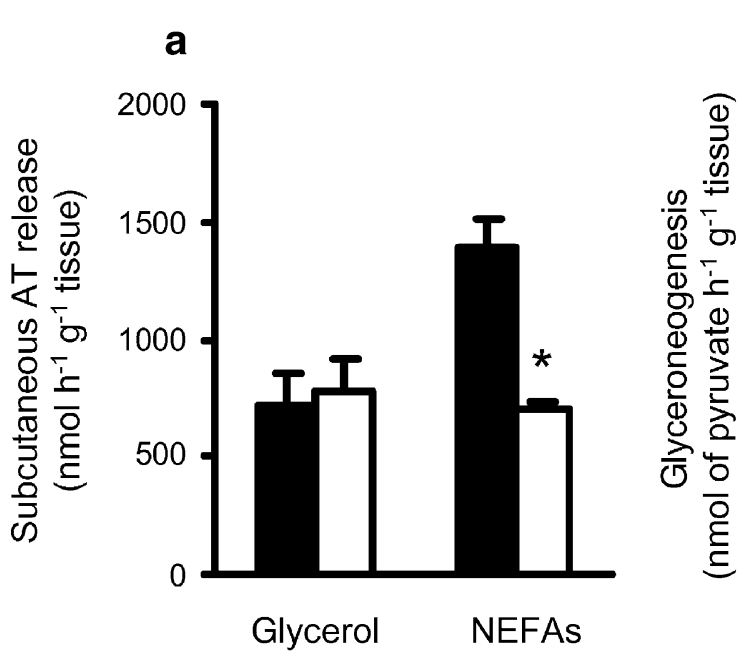

b

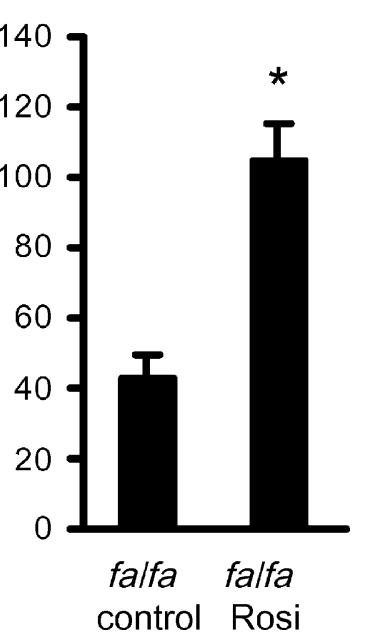

C

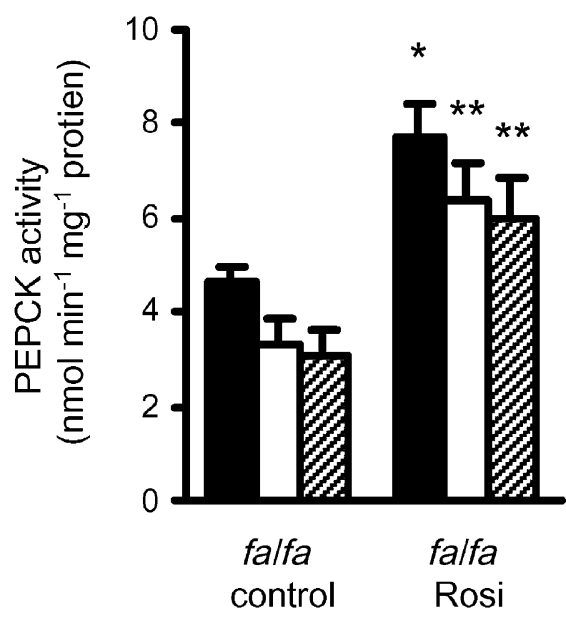

Fig. 2 Effect of rosiglitazone on metabolic parameters and on PEPCK-C activity in obese Zucker rat ( $f a / f a)$ adipose tissues. Glycerol and NEFA release in the incubation medium (a) and glyceroneogenic activity (b) were monitored from s.c. adipose tissue $(A T)$ from control (black bars) and rosiglitazone-treated (white bars) falfa rats. (c)

The expression of PCK1 mRNA showed a strong and significant 2.5 -fold upregulation (150\% above placebo) following the 12-week thiazolidinedione treatment (Fig. 3). In contrast, $P C K 2$, soluble glycerol-3-phosphate dehydrogenase $(G P D 1)$, pyruvate kinase dehydrogenase, isoenzyme $4(P D K 4)$, retinoid $\mathrm{X}$ receptor $\alpha(R X R A)$ and cyclophilin mRNAs remained unaffected. Among the genes described above in our rodent model, only FABP4 was previously shown to be upregulated in the same cohort [8].

Rosiglitazone regulation of gene expression in ex vivo cultured human adipose tissue explants To explore further the regulation of these genes in humans, we cultured s.c. adipose tissue explants obtained from healthy overweight women having elective plastic surgery. Since culture of

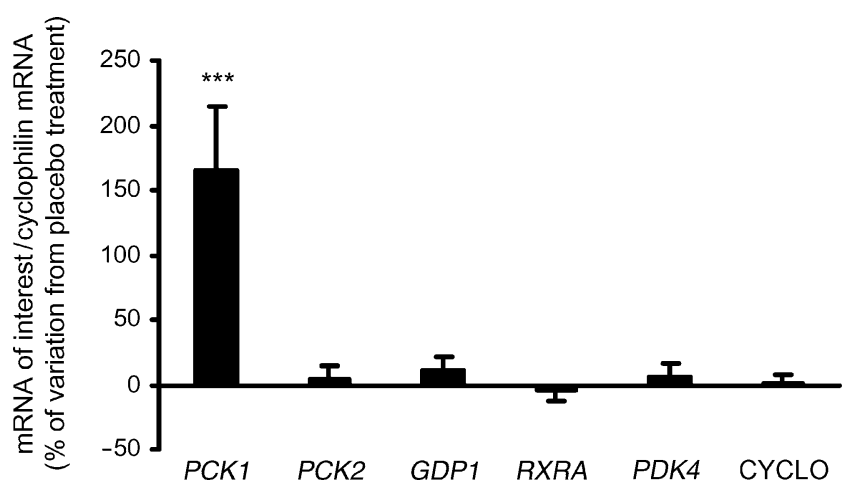

Fig. 3 Effect of rosiglitazone treatment on gene expression in s.c. adipose tissue from type 2 diabetic patients. Effect of the 12-week treatment with rosiglitazone or placebo on the indicated mRNAs. Data were normalised to cyclophilin $(C Y C L O)$ mRNA and expressed as a percent of variations from placebo. Results are means \pm SEM obtained from the 24 subjects. $* * * p<0.001$ vs placebo
PEPCK activity was measured in s.c. (black bars), periepididymal (white bars) and retroperitoneal (hatched bars) adipose tissues from control and rosiglitazone-treated $f a / f a$ rats. Results are means \pm SEM from eight rats in each group. ${ }^{*} p<0.05$ vs $f a / f a$ rats; ${ }^{* *} p<0.01$ vs $f a / f a$ rats

adipose tissue is preceded by several steps (surgery, transfer and dissection) which could alter adipocyte gene expression [30], we verified the expression of TNF and VEGFA coding, respectively, for tumour necrosis factor alpha and vascular endothelial growth factor, which are markers for hypoxia and inflammation, respectively, in our experimental conditions. Both genes remained stably expressed for as long as 3 days in culture, as was GAPDH (data not shown).

Treatment of explants with $1 \mu \mathrm{mol} / 1$ rosiglitazone caused a progressive increase in the abundance of the PCK1 transcript that reached a maximum of 9-fold at $14 \mathrm{~h}$ and decreased thereafter (Fig. 4a). A late and modest twofold increase was observed for $F A B P 4$ mRNA at $24 \mathrm{~h}$, while the expression of $P C K 2, G Y K$ and $L P L$ remained unchanged whatever the time of treatment (Fig. 4a). To examine a possible effect of rosiglitazone on PCK1 mRNA stability, we first treated explants with rosiglitazone for $5 \mathrm{~h}$, then with the transcription inhibitor 5,6-dichloro-1 $\beta$-D-ribofuranosyl benzimidazole (DRB) in the presence or absence of rosiglitazone and monitored $P C K 1$ mRNA concentration over time. No change in PCK1 mRNA half-life was observed under these conditions (Fig. 4b). Calculated half-life was about $5 \mathrm{~h}$ in these conditions, in agreement with what had already been observed in 3T3-F442A adipocytes [31]. While DRB had only a mild effect on basal PCK1 mRNA, it inhibited rosiglitazone induction (Fig. 4c). Besides, the protein synthesis inhibitor puromycin affected neither basal nor rosiglitazone-stimulated $P C K 1$ mRNA, showing that this gene was a primary target for the drug (Fig. 4c). Altogether these results strongly suggested that, as expected from what was already observed in the 3T3-F442A rodent adipocyte cell line, rosiglitazone directly induced $P C K 1$ transcription in human adipose tissue [32]. 
Fig. 4 Effect of rosiglitazone (Rosi) on gene expression in human s.c. adipose tissue. a PCK1 (black bars), PCK2 (white bars), GYK (hatched bars), GPD1 (grey bars), FABP4 (vertical hatched bars) and LPL (dotted bars) mRNAs from human s.c. explants were analysed by real-time RT-PCR. b Human adipose tissue explants were first treated (white triangles) or not (black triangles) for $5 \mathrm{~h}$ with rosiglitazone at $1 \mu \mathrm{mol} / \mathrm{l}$. The horizontal and vertical bars indicate how halflife was evaluated. Then DRB $(25 \mu \mathrm{g} / \mathrm{ml})$ was added and RNA isolated as indicated. c Human adipose tissue explants were treated for $5 \mathrm{~h}$ with rosiglitazone at $1 \mu \mathrm{mol} / 1$ in the absence or presence of DRB $(25 \mu \mathrm{g} / \mathrm{ml})$ or puromycin $\left(10^{-5} \mathrm{~mol} / \mathrm{l}\right)$. cont, control. Transcripts were analysed in triplicate by real-time RT-PCR. Throughout data were normalised to GAPDH values and expressed as a per cent of control. Data points are means \pm SEM from six individuals at 5 and $24 \mathrm{~h}$ and four individuals at 14 h. ${ }^{*} p<0.05$ vs control; $* * * p<0.001$ vs control a

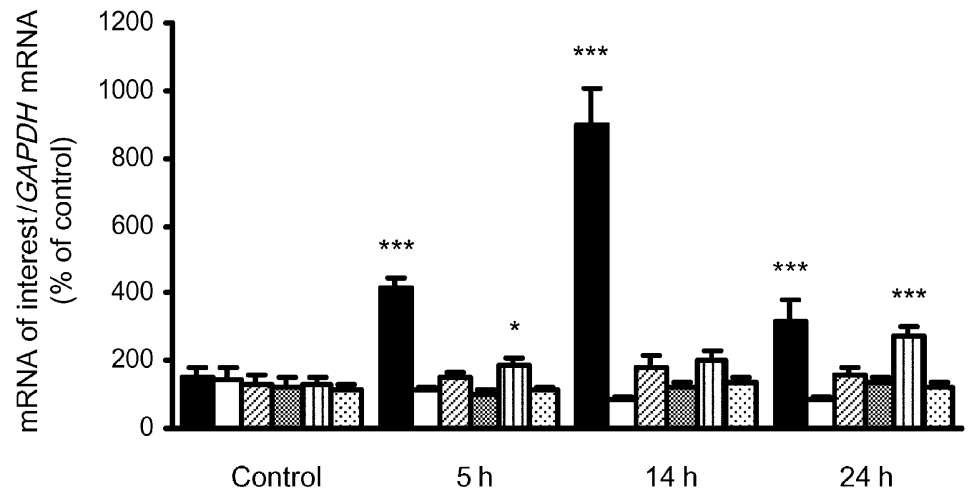

b

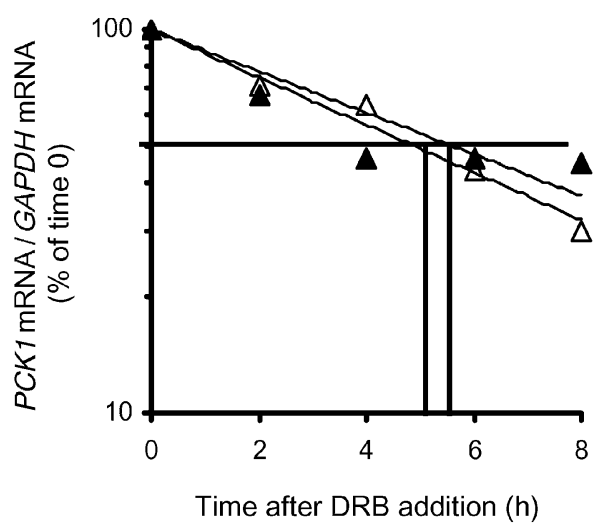

C

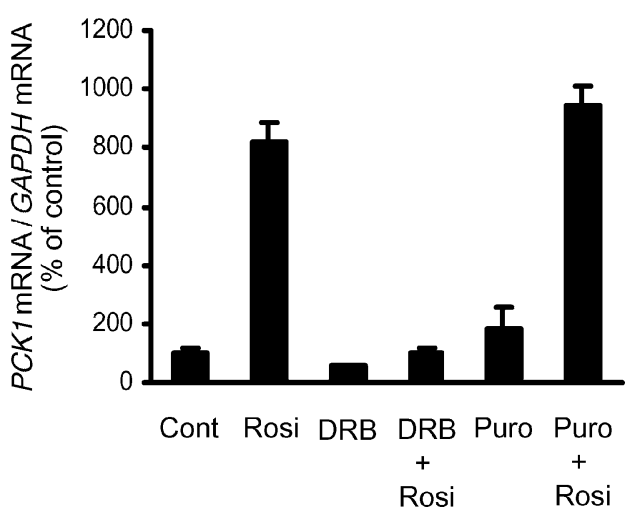

Additionally, PEPCK-C protein, PEPCK activity and incorporation of $\left[1-{ }^{14} \mathrm{C}\right]$ pyruvate into lipids were significantly increased about 95,60 and $50 \%$, respectively, at $18 \mathrm{~h}$ of rosiglitazone treatment (ESM Fig. 1).

\section{Discussion}

Among the pathways that thiazolidinediones alter in adipose tissue, fatty acid re-esterification has been described as an important one. Thiazolidinediones induce G3P synthesis through glyceroneogenesis and glycerol phosphorylation [33]. We showed that glyceroneogenesis was the main contributor pathway for fatty acid reesterification in rat adipose tissue in both basal and thiazolidinedione-stimulated conditions [19]. This result was reinforced by elegant in vivo experiments from Chen et al. [34], in which mass isotopomer analyses in mice confirmed the major contribution of glyceroneogenesis to thiazolidinedione-induced triacylglycerol synthesis, with a very minor role of glycerol phosphorylation. One important observation of our present work is that the administration of rosiglitazone to insulin-resistant rats induced an increase in glyceroneogenesis, which was accompanied by an improvement in dyslipidaemia, as shown by the large decrease in plasma triacylglycerol. Similar observations were previously reported in humans, in whom thiazolidinediones induced a reduction in postprandial plasma triacylglycerol $[8,35]$. As expected, a strong correlation was also shown between the glyceroneogenic flux of the tissue and the release of NEFA in the incubation medium. As a consequence, we observed a large decrease in plasma NEFA concentration in agreement with the role that glyceroneogenesis is playing in G3P synthesis required for fatty acid esterification after a high-fat or high-protein carbohydrate-free diet and for reesterification during fasting [36, 37]. According to the minor role of glycerol phosphorylation in this process, we could not detect any variation in glycerol release whether rats were treated with rosiglitazone or not, in agreement with our previous studies, in which either a very mild decrease or no variation in glycerol release was observed [18]. We can thus easily attribute the improvement in plasma dyslipidaemia to the early induction of fatty acid reesterification linked to glyceroneogenesis in response to thiazolidinediones.

Indeed, PCK1 mRNA was strongly induced in s.c., periepididymal and retroperitoneal adipose tissues at 4 days of rosiglitazone treatment, while expression of the gene encoding the mitochondrial isoform of PEPCK, PEPCK-M, remained unaffected. Expression of the Fabp4 and Gyk 
genes was also augmented. Similar results were obtained previously in rodent adipose tissue [38]. These changes in gene expression are reminiscent of what was shown in 3T3F442A adipocytes, in which, however, Pck 1 is by far the earliest and directly responsive gene [32].

As a consequence of these rapid and profound changes in adipose tissue gene expression and metabolism, blood NEFA concentration decreased. This decrease would lead to a diminished fatty acid flux towards the liver, resulting in a reduction in triacylglycerol synthesis and export to the blood as VLDL. Indeed, fatty acids are taken up and used by the liver in proportion to their delivery rate and hepatic VLDL synthesis and secretion is directly linked to substrate availability [39]. We noticed the absence of a rosiglitazone effect on liver PEPCK-C, in agreement with the results from Way et al. [2], who showed that a 24-h treatment of Zucker diabetic fatty rats with a PPAR $\gamma$ agonist had no effect on liver PCK1 mRNA, whereas at 7 days of exposure an $80 \%$ decrease was observed [2]. These observations agree with the expected glucose-lowering role of thiazolidinediones, which would increase adipose tissue re-esterification in the short term but would later on decrease gluconeogenesis.

The second important observation from our present study is that rosiglitazone administration to type 2 diabetes patients for 12 weeks induced $P C K 1 \mathrm{mRNA}$, but not $P C K 2$ mRNA, in s.c. adipose tissue at a much higher incremental level than that of any other gene tested in the same cohort $[8,40,41]$. Similar results were obtained by Bogacka et al. in a cohort of pioglitazone-treated type 2 diabetes patients [22]. However, our data showed no effect of the drug on GPD1 mRNA, in contrast to the $30 \%$ increase observed in the Bogacka study. These results reinforced our view that $P C K 1$ is the major thiazolidinedione target gene in human adipose tissue, as in rodents. Indeed, there was little or no induction in $G Y K$ expression in adipose tissue in either cohort [22, 42].

The third important observation from our study is that in adipose tissue explants from humans only $P C K 1$, and to a lesser extent $F A B P 4$, were acutely induced by rosiglitazone. Guan et al. showed an induction of $G Y K$ mRNA in primary human adipocytes [38]. However, in the study of Guan et al., primary cultures were treated for 10 days with ciglitazone, which could correspond to a differentiation effect due to the long-term treatment. The situation is quite different from what we show in adipose tissue explants treated with rosiglitazone for $24 \mathrm{~h}$ at most and in which a differentiation effect of the drug is unlikely to occur. Previous data from our laboratory showed that adipose tissue explants, from lean $\left(\mathrm{BMI}<27 \mathrm{~kg} / \mathrm{m}^{2}\right)$ but not overweight subjects, exposed for 3 days to rosiglitazone resulted in an increase in GYK activity [21]. These data are in agreement with the present study in which rosiglitazone action was monitored in short-term treated (5-24 h) adipose tissue explants from overweight subjects (mean $\mathrm{BMI}=$ $30.3 \mathrm{~kg} / \mathrm{m}^{2}$ ) of a different cohort.

The demonstration that PPAR $\gamma$ ligands acutely regulate $P C K 1$ expression in human adipose tissue agrees with what has been shown earlier by our laboratory and others in rodent adipocytes or adipose tissue [32, 43, 44]. We show additionally here that $P C K 1$ transcription is the affected step in human adipose tissue and that no post-transcriptionnal effect occurs in response to the thiazolidinedione. The demonstration that rosiglitazone action does not require protein synthesis strongly suggests that the whole machinery for stimulating transcription of this gene is present and functional in human adipocytes. This does not appear to be the case for the GYK which, at least in 3T3-L1 adipocytes, requires complex events to be activated at the transcriptional level, thus explaining the delayed thiazolidinedione induction [45]. Therefore, it is not surprising that the $P C K 1$ and the associated metabolic pathway, i.e. glyceroneogenesis, are acute rosiglitazone targets. We propose that this pathway is the initially affected step in response to thiazolidinedione and that the early occurring stimulation of fatty acid re-esterification is the major effect of this type of drug in human adipose tissue, as in rodents.

Acknowledgements The authors thank P. Juraver (INSERM, UMRS747) for rat handling, J. G. Lindsay (University of Glasgow, UK) for providing PDH-E2 antibody (see ESM) and V. Nivet (Paris Descartes University, France) for triacylglycerol determination. We thank L. Benelli (Plastic Surgery Unit, Hartman Clinic, Paris, France) for his helpful involvement with human studies. This work was supported by INSERM, Paris Descartes University and by a grant from the French Association for the study of Diabetes and Metabolic Diseases ALFEDIAM-GlaxoSmithKline (to C. Forest). T. Cadoudal is a recipient of a Fellowship from the French National Education and Research Department. J. M. Blouin is a recipient of a Fellowship from the French National League Against Cancer (League Nationale Contre le Cancer).

Duality of interest There is no duality of interest.

\section{References}

1. Lehmann JM, Moore LB, Smith-Oliver TA, Wilkison WO, Willson TM, Kliewer SA (1995) An antidiabetic thiazolidinedione is a high affinity ligand for peroxisome proliferator-activated receptor gamma (PPAR gamma). J Biol Chem 270:12953-12956

2. Way JM, Harrington WW, Brown KK et al (2001) Comprehensive messenger ribonucleic acid profiling reveals that peroxisome proliferator-activated receptor gamma activation has coordinate effects on gene expression in multiple insulin-sensitive tissues. Endocrinology 142:1269-1277 
3. Oakes ND, Thalen PG, Jacinto SM, Ljung B (2001) Thiazolidinediones increase plasma-adipose tissue FFA exchange capacity and enhance insulin-mediated control of systemic FFA availability. Diabetes 50:1158-1165

4. Okuno A, Tamemoto $H$, Tobe $K$ et al (1998) Troglitazone increases the number of small adipocytes without the change of white adipose tissue mass in obese Zucker rats. J Clin Invest 101:1354-1361

5. Chaput E, Saladin R, Silvestre M, Edgar AD (2000) Fenofibrate and rosiglitazone lower serum triglycerides with opposing effects on body weight. Biochem Biophys Res Commun 271:445-450

6. Miyazaki Y, Glass L, Triplitt C et al (2001) Effect of rosiglitazone on glucose and non-esterified fatty acid metabolism in Type II diabetic patients. Diabetologia 44:2210-2219

7. Mayerson AB, Hundal RS, Dufour S et al (2002) The effects of rosiglitazone on insulin sensitivity, lipolysis, and hepatic and skeletal muscle triglyceride content in patients with type 2 diabetes. Diabetes 51:797-802

8. Tan GD, Fielding BA, Currie JM et al (2005) The effects of rosiglitazone on fatty acid and triglyceride metabolism in type 2 diabetes. Diabetologia 48:83-95

9. James AP, Watts GF, Mamo JC (2005) The effect of metformin and rosiglitazone on postprandial lipid metabolism in obese insulin-resistant subjects. Diabetes Obes Metab 7:381-389

10. Boden G, Homko C, Mozzoli M, Showe LC, Nichols C, Cheung $\mathrm{P}$ (2005) Thiazolidinediones upregulate fatty acid uptake and oxidation in adipose tissue of diabetic patients. Diabetes 54:880-885

11. Vaughan M (1962) The production and release of glycerol by adipose tissue incubated in vitro. J Biol Chem 237:3354-3358

12. Jensen MD, Ekberg K, Landau BR (2001) Lipid metabolism during fasting. Am J Physiol Endocrinol Metab 281:E789-E793

13. Van Harmelen V, Reynisdottir S, Cianflone K et al (1999) Mechanisms involved in the regulation of free fatty acid release from isolated human fat cells by acylation-stimulating protein and insulin. J Biol Chem 274:18243-18251

14. Beale EG, Hammer RE, Antoine B, Forest C (2002) Glyceroneogenesis comes of age. Faseb J 16:1695-1696

15. Therriault DG, Hubbard RW, Mellin DB (1969) Endocrine control of fat mobilization in the isolated fat cells of cold-exposed rats. Lipids 4:413-420

16. Reshef L, Hanson RW, Ballard FJ (1969) Glyceride-glycerol synthesis from pyruvate. Adaptive changes in phosphoenolpyruvate carboxykinase and pyruvate carboxylase in adipose tissue and liver. J Biol Chem 244:1994-2001

17. Kruszynska YT, McCormack JG, McIntyre N (1990) Effects of non-esterified fatty acid availability on insulin stimulated glucose utilisation and tissue pyruvate dehydrogenase activity in the rat. Diabetologia 33:396-402

18. Kalhan SC, Mahajan S, Burkett E, Reshef L, Hanson RW (2001) Glyceroneogenesis and the source of glycerol for hepatic triacylglycerol synthesis in humans. J Biol Chem 276:12928-12931

19. Tordjman J, Chauvet G, Quette J, Beale EG, Forest C, Antoine B (2003) Thiazolidinediones block fatty acid release by inducing glyceroneogenesis in fat cells. J Biol Chem 278:18785-18790

20. Duplus E, Benelli C, Reis AF, Fouque F, Velho G, Forest C (2003) Expression of phosphoenolpyruvate carboxykinase gene in human adipose tissue: induction by rosiglitazone and genetic analyses of the adipocyte-specific region of the promoter in type 2 diabetes. Biochimie 85:1257-1264

21. Leroyer SN, Tordjman J, Chauvet G et al (2006) Rosiglitazone controls fatty acid cycling in human adipose tissue by means of glyceroneogenesis and glycerol phosphorylation. J Biol Chem 281:13141-13149

22. Bogacka I, Xie H, Bray GA, Smith SR (2004) The effect of pioglitazone on peroxisome proliferator-activated receptor-gamma target genes related to lipid storage in vivo. Diabetes Care 27:1660-1667

23. Chomczynski P, Sacchi N (1987) Single-step method of RNA isolation by acid guanidinium thiocyanate-phenol-chloroform extraction. Anal Biochem 162:156-159

24. Chang HC, Lane MD (1966) The enzymatic carboxylation of phosphoenolpyruvate, II. Purification and properties of liver mitochondrial phosphoenolpyruvate carboxykinase. J Biol Chem 241:2413-2420

25. Srere PA (1969) Citrate synthase. In: Lowenstein JM (ed) Methods in enzymology XIII. Academic, New York, pp 3-11

26. Bligh EG, Dyer WJ (1959) A rapid method of total lipid extraction and purification. Can J Biochem Physiol 37:911-917

27. Bradford MM (1976) A rapid and sensitive method for the quantitation of microgram quantities of protein utilizing the principle of protein-dye binding. Anal Biochem 72:248-254

28. Dugail I, Quignard-Boulange A, Le Liepvre X, Ardouin B, Lavau M (1992) Gene expression of lipid storage-related enzymes in adipose tissue of the genetically obese Zucker rat. Co-ordinated increase in transcriptional activity and potentiation by hyperinsulinaemia. Biochem J 281(Pt 3):607-611

29. Ballard FJ, Hanson RW, Leveille GA (1967) Phosphoenolpyruvate carboxykinase and the synthesis of glyceride-glycerol from pyruvate in adipose tissue. J Biol Chem 242:2746-2750

30. Gesta S, Lolmede K, Daviaud D et al (2003) Culture of human adipose tissue explants leads to profound alteration of adipocyte gene expression. Horm Metab Res 35:158-163

31. Franckhauser-Vogel S, Antras-Ferry J, Robin D, Robin P, Forest C (1997) Transcriptional and posttranscriptional mechanisms of glucocorticoid-mediated repression of phosphoenolpyruvate carboxykinase gene expression in adipocytes. J Cell Biochem 66:386-393

32. Glorian M, Duplus E, Beale EG, Scott DK, Granner DK, Forest C (2001) A single element in the phosphoenolpyruvate carboxykinase gene mediates thiazolidinedione action specifically in adipocytes. Biochimie 83:933-943

33. Cadoudal T, Leroyer S, Reis AF et al (2005) Proposed involvement of adipocyte glyceroneogenesis and phosphoenolpyruvate carboxykinase in the metabolic syndrome. Biochimie 87:27-32

34. Chen JL, Peacock E, Samady W et al (2005) Physiologic and pharmacologic factors influencing glyceroneogenic contribution to triacylglyceride glycerol measured by mass isotopomer distribution analysis. J Biol Chem 280:25396-25402

35. van Wijk JP, de Koning EJ, Castro Cabezas M, Rabelink TJ (2005) Rosiglitazone improves postprandial triglyceride and free fatty acid metabolism in type 2 diabetes. Diabetes Care 28:844-849

36. Antras-Ferry J, Robin P, Robin D, Forest C (1995) Fatty acids and fibrates are potent inducers of transcription of the phosphenolpyruvate carboxykinase gene in adipocytes. Eur J Biochem 234:390 396

37. Brito SC, Festuccia WL, Kawashita NH et al (2006) Increased glyceroneogenesis in adipose tissue from rats adapted to a highprotein, carbohydrate-free diet: role of dietary fatty acids. Metabolism 55:84-89

38. Guan HP, Li Y, Jensen MV, Newgard CB, Steppan CM, Lazar MA (2002) A futile metabolic cycle activated in adipocytes by antidiabetic agents. Nat Med 8:1122-1128

39. Lewis GF, Carpentier A, Adeli K, Giacca A (2002) Disordered fat storage and mobilization in the pathogenesis of insulin resistance and type 2 diabetes. Endocr Rev 23:201-229

40. Riserus U, Tan GD, Fielding BA et al (2005) Rosiglitazone increases indexes of stearoyl-CoA desaturase activity in humans: link to insulin sensitization and the role of dominant-negative mutation in peroxisome proliferator-activated receptor-gamma. Diabetes 54:1379-1384 
41. Tan GD, Debard C, Funahashi $T$ et al (2005) Changes in adiponectin receptor expression in muscle and adipose tissue of type 2 diabetic patients during rosiglitazone therapy. Diabetologia 48:1585-1589

42. Tan GD, Debard C, Tiraby C et al (2003) A "futile cycle" induced by thiazolidinediones in human adipose tissue? Nat Med 9:811812. (author reply 812)

43. Hallakou S, Doare L, Foufelle F et al (1997) Pioglitazone induces in vivo adipocyte differentiation in the obese Zucker fa/fa rat. Diabetes 46:1393-1399

44. Tontonoz P, Hu E, Devine J, Beale EG, Spiegelman BM (1995) PPAR gamma 2 regulates adipose expression of the phosphoenolpyruvate carboxykinase gene. Mol Cell Biol 15:351-357

45. Guan HP, Ishizuka T, Chui PC, Lehrke M, Lazar MA (2005) Corepressors selectively control the transcriptional activity of PPARgamma in adipocytes. Genes Dev 19:453-461 